\title{
A CRATERA DE IMPACTO DO CERRO DO JARAU-RS, BRASIL:
}

\section{UMA ABORDAGEM GEOTURÍSTICA}

\author{
Joana Paula Sánchez ${ }^{1} \&$ Maria da Glória Motta Garcia ${ }^{2}$
}

\begin{abstract}
1 -Universidade Estadual Paulista Júlio de Mesquita Filho. Programa de Pós-graduação em Geologia Regional. Av. 24ạ, 1515, Bairro Bela Vista. CEP: 13506-900 Rio Claro-SP. joana_paula_sanchez@yahoo.com.br

2 - Universidade de São Paulo-Núcleo GeoHereditas. Rua do Lago, 562-Cidade Universitária. CEP: 05508-080. São Paulo-SP.mgmgarcia@usp.br
\end{abstract}

Resumo: Crateras de impacto por meteorito são formações raras no planeta e de extrema importância para o conhecimento da evolução geológica e biológica da Terra por se tratarem de eventos catastróficos que causaram extinções em massa e movimentaram camadas geológicas. No Brasil sete crateras de impacto estão cientificamente comprovadas, dentre estas, quatro já classificadas como possíveis sítios geológicos. A área objeto deste trabalho, o Cerro do Jarau, está localizada no sudoeste do Estado do Rio Grande do Sul, na divisa com o Uruguai e insere-se no contexto geológico da Bacia do Paraná. Trata-se de uma feição semicircular de aproximadamente oito quilômetros de diâmetro, com cristas elevadas, que se diferenciamgeomorfologicamente do Pampa Gaúcho. A região constitui-se num bom exemplo de geossítio no qual o patrimônio geológico pode associar-se ao patrimônio imaterial, entre eles valores culturais e arqueológicos, para impulsionar o turismo local com o apoio de estratégias de geoconservação e um plano geoturístico.

Palavras chave: Crateras de Impacto, Geoconservação, Geoturismo, Patrimônio Geológico.

ABSTRACT: THE IMPACT CRATER OF CERRO DO JARAU, BRAZIL: A GEOTURISTIC APPROACH.Meteorite impact craters are rare formations on the planet and of utmost importance for the understanding of the biological and geological evolution of the Earth because they are registers of catastrophic events that caused mass extinctions and geological movements. In Brazil seven impact craters are scientifically proven, among these four already classified as potential geological sites. The area object of this work, Cerro do Jarau, is located southwest of Rio Grande do Sul State, at the limit with Uruguay and is part of the geological context of the Paraná Basin. It is a semicircular feature with approximately eight miles in diameter, with high ridges, which differ geomorphologicallyof the Pampa Gaúcho. The region constitutes a good example of geosite where geological heritage can join intangible heritage, including archaeological and cultural values, to boost local tourism with the support of geoconservation strategies and a geotourism plan.

Keywords: Impact craters, geoconservation, geoturism, geological heritage.

\section{INTRODUÇÃO}

Geoturismo é um segmento do turismo relacionado à identificação, à conservação e à disseminação do patrimônio natural não-biótico, essencialmente geológico e geomorfológico (Dowling \& Newsome 2010; Newsome \& Dowling 2006, 2010; Nascimento et al. 2007; Moreira 2010).

O conceito inicial foi proposto por Hose (1995) para conceituar o tipo de turismo que utiliza como atrativos feições geológicas diversas, tais como formações rochosas, estruturas e paisagens. Esta conceituação tinha como principal característica o fato delimitar os atrativos aos seus aspectos físicos, em detrimento aos valores culturais, históricos e econômicos da área abordada. Ao longo dos anos, entretanto, este conceito foi sendo gradualmente modificadoe passou a incluir estes valores (Hose, 2008), com o acréscimo do benefício à população, principalmente no que concerne ao desenvolvimento sustentável.

Neste sentido, as abordagens mais recentes em termos de Geoturismo sugerem que as atividades ligadas ao tema devem ter como complemento natural a divulgação dos conhecimentos adquiridos em termos de integração com outros aspectos do patrimônio da região, criando links que interliguem os valores geológicos com aqueles relacionados à cultura, ao modo de ocupação do território e à economia, entre outros. Associado a estes aspectos estão o conhecimento do meio como um todo, incluindo flora, fauna e Educação Ambiental, além de estratégias de inclusão das comunidades locais na preservação do patrimônio.

A Declaração de Arouca, redigida durante o Congresso Internacional de Geoturismo (Portugal, 2011), diz que o geoturismo passa a ser entendido como "... o turismo que sustenta e incrementa a identidade de um território, considerando a sua geologia, ambiente, cultura, valores estéticos, patrimônio e o bem-estar dos seus residentes...". O "Centro para Destinos Sustentáveis", da National Geographic, define o Geoturismo como "... o turismo que mantém ou aprimora o caráter geográfico de um lugar, seu ambiente, sua cultura, sua estética, seu patrimônio e o bem-estar de seus habitantes", definição que, apesar de ser mais completa em relação às novas abordagens, não leva em conta os aspectos geológicos e se atém à geografia.'

As vantagens de expandir o conceito de geoturismo para além do turismo geológico foram discutidas por Martini et al. (2012), que argumentam que, sendo o geoturismo uma atividade econômica como qualquer outro tipo de turismo, deve necessariamente gerar recursos, o que está diretamente relacionado à quantidade de turistas que visitam a região. Sendo as geociências em geral pouco conhecidas da maioria da população, entende-se que, ao agregar outros valores ao conhecimento geocientífico, o turismo pode se tornar mais efetivo e atrair pessoas que usualmente não estariam interessadas em geociências, mas que acabam recebendo as informações disponíveis. 
Um outro aspecto que deve ser levado em conta no Geoturismo é a divulgação do conhecimento geológico para públicos não especializados, um desafio que advém principalmente da dificuldade em traduzir e interpretar o meio físico de uma forma coerente e, ao mesmo tempo, apropriada. Desde o surgimento do conceito de interpretação ambiental (Tilden, 1957), o aprendizado do meio natural tem sido preferencialmente realizado por meio de atividades práticas e associações com a memória prévia das pessoas, ao invés da simples comunicação de informações. Moreira (2011) apresenta, para o âmbito nacional, conceitos de educação e interpretação ambiental e sua relação com o patrimônio geológico, uma abordagem que tem sido denominada interpretação geológica, como no caso de trilhas (Garcia et al. 2013). Uma das formas mais comuns de transmitir informações são os painéis interpretativos, normalmente colocados no geossítio, além de panfletos, modelos, maquetes e outras.

O Brasil possui um inegável potencial turístico, marcado principalmente pelo patrimônio natural, mas associado grandemente aos aspectos culturais e históricos. Apesar disso, são relativamente poucas as iniciativas relacionadas ao Geoturismo, mesmo levando em consideração apenas os aspectos físicos. Os motivos para esta falta de interesse estão o (quase) total desconhecimento, por parte da maioria da população, de conceitos geológicos básicos e a falta de programas sistemáticos de inventário do patrimônio geológico tanto em nível nacional como estadual ou local, vitais para a seleção de geossítios relevantes que possam servir de base para implementar programas geoturísticos e de preservação da paisagem.

Por outro lado, a despeito da (ainda) pouca divulgação no Brasil, os temas relacionados à Geoconservação vêm apresentando crescente interesse da comunidade geocientífica. Segundo a Declaração internacional dos direitos a memória da Terra (Digne, 1991) “Assim como cada vida humana

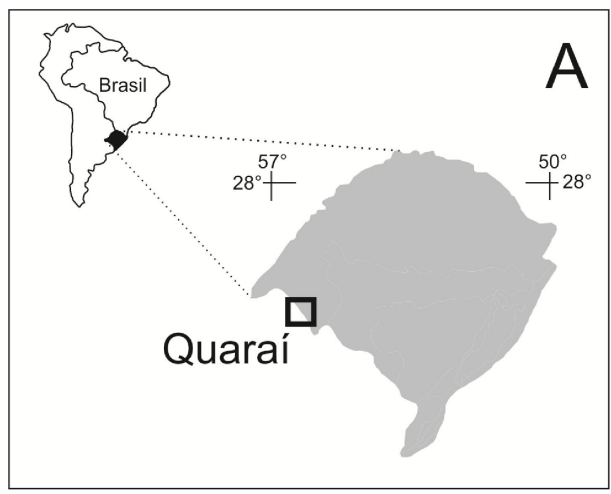

é considerada única, chegou à altura de reconhecer, também, o caráter único da Terra".

Como objetivos principais da Geoconservação estão a preservação da diversidade natural de aspectos geológicos tais como materiais e processos (geodiversidade), geomorfológicos (formas da paisagem) e do solo, mantendo sua evolução natural - velocidade e intensidade(Brilha,2005). Em muitospaíses, principalmenteda Europa, o conhecimento geológico mais detalhado dos territórios permiteque os estudos sobre o patrimônio geológico sejam mais diretos, mas no Brasil, em que existe muita heterogeneidade no conhecimento geológico dos diversos Estados, se faz necessário um plano de ação para que este patrimônio seja definido, a começar pelo inventário dos geossítios, a partir do qual torna-se possível o estabelecimento de estratégias de geoconservação.

Neste trabalho descreve-se a região do Cerro do Jarau, situada no Estado do Rio Grande do Sul, próximo à divisa com o Uruguai (Figura 1A) e que tem na serra homônima uma feição única, verificada com facilidade em imagem de satélite, na qual destaca-se uma estrutura semicircular anômala de caráter pontual (Figura 1B). O local está inserido no contexto geológico da Bacia do Paraná, sendo estudado desde meados da década de 1960 até os dias de hoje. Os detalhes sobre sua formação são ainda controversos, mas sua origem a partir de uma cratera de impacto é a explicação hoje para sua formação, o que faz da estrutura uma feição rara no Planeta. Por este motivo, estudos acerca do inventário deste patrimônio geológico e posterior conservação têm sido realizados, incluindo as evidências que comprovam ser uma cratera de impacto erodida, suas principais feições de deformação, os valores culturais e o bioma. 0 objetivo deste trabalho é descrever os principais aspectos relacionados a este geossítio, incluindoos valores geológicos, culturais, didáticos e turísticos, buscando sua integração e a apresentação de propostas de Geoconservação e de Geoturismo de acordo com o seu sentido mais amplo e moderno.

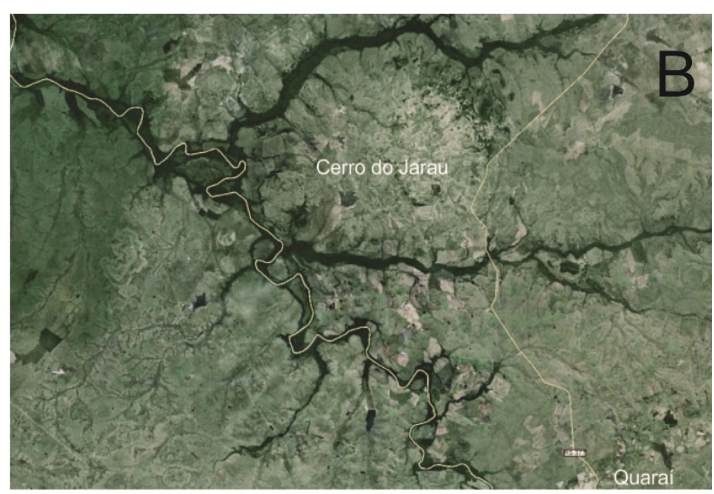

Figura 1 - A) Localização do Cerro do Jarau (elipse azul) e as cidades de Quaraí e Uruguaiana, no Estado do Rio Grande do Sul. B) Imagem de satélite da região do Cerro do Jarau. Notar a feição circular, com serras proeminentes, na parte norte. Fonte: Google Earth (imagem tratada 


\section{LOCALIZAÇÃO}

A estrutura localiza-se no extremo sudoeste do Estado do Rio Grande do Sul, distante $20 \mathrm{~km}$ a norte da cidade de Quaraí e $105 \mathrm{~km}$ a leste da cidade de Uruguaiana (Figura 1).

\section{CONTEXTO GEOLÓGICO}

A área está inserida na Bacia do Paraná,

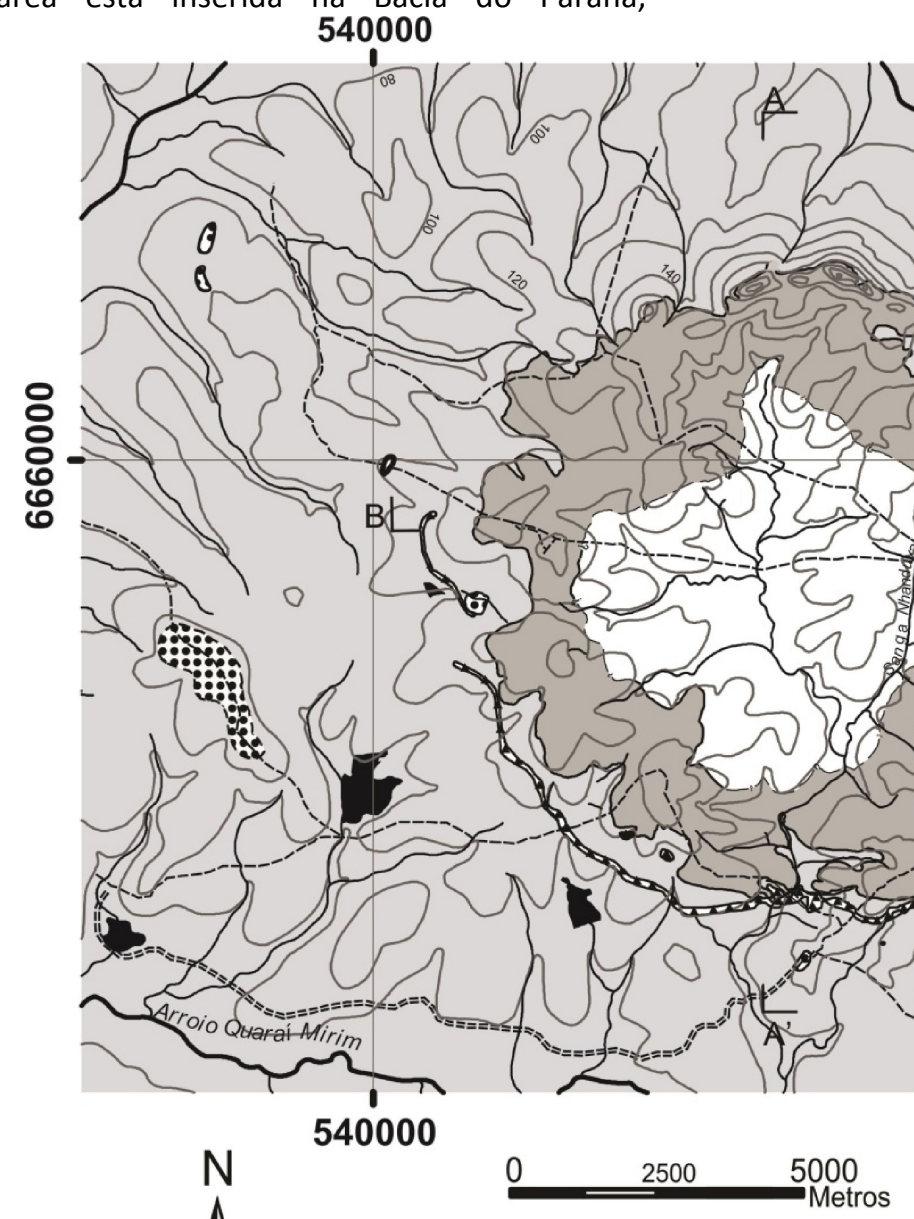

Equidistância das Curvas de Nivel: $20 \mathrm{~m}$

Datum Horizontal: Córrego Alegre - Minas Gerais

Datum Vertical: Marégrafo de Torres - Rio Grande do Sul
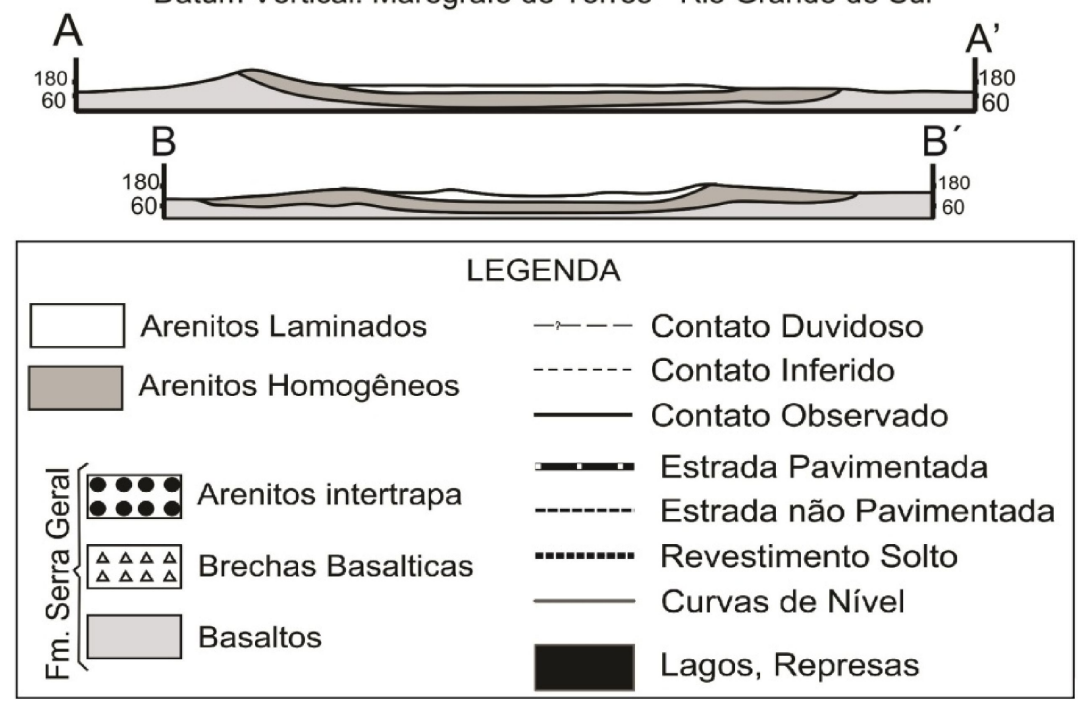

Figura 2 - Mapa geológico da região do Cerro do Jarau (Sánchez, 2013). aflorando rochas das Formações Serra Geral e Botucatu, bem como rochas sedimentares posteriores aos derrames basálticos da Formação Serra Geral (Simões et al, no prelo). São reconhecidos na área basaltos, brechas ígneas, arenitos intertrapa, arenitos conglomeráticos, arenitos homogêneos e arenitos laminados (Figura 2).

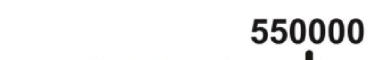


A estrutura foi reconhecida inicialmente por Grehs (1969) que interpretou que se tratava de um domo estrutural formado por tectônica pós-arenito Botucatu e pré-derrames basálticos da Formação Serra Geral. Trabalhos posteriores como Moreira (1980), Lisboa et al. (1987), Schuck\& Lisboa (1988), Lourenço (2007), Cróstaet al. (2010) e Philippet al. (2010) ressaltam o padrão de uma estrutura com o centro soerguido, com a ocorrência de arenitos da Formação Botucatu no centro e basaltos da Formação Serra Geral na Borda, sendo levantada a suspeita de se tratar de uma estrutura causada por impacto de meteorito (Lisboa et al. 1987, Lourenço 2007, Cróstaet al. 2010 \&Philippet al. 2010).

Estudos posteriores de detalhe chegam a conclusãoque a estrutura é uma cratera de impacto e que apresenta feições de deformação nas diversas unidades que afloram no local.
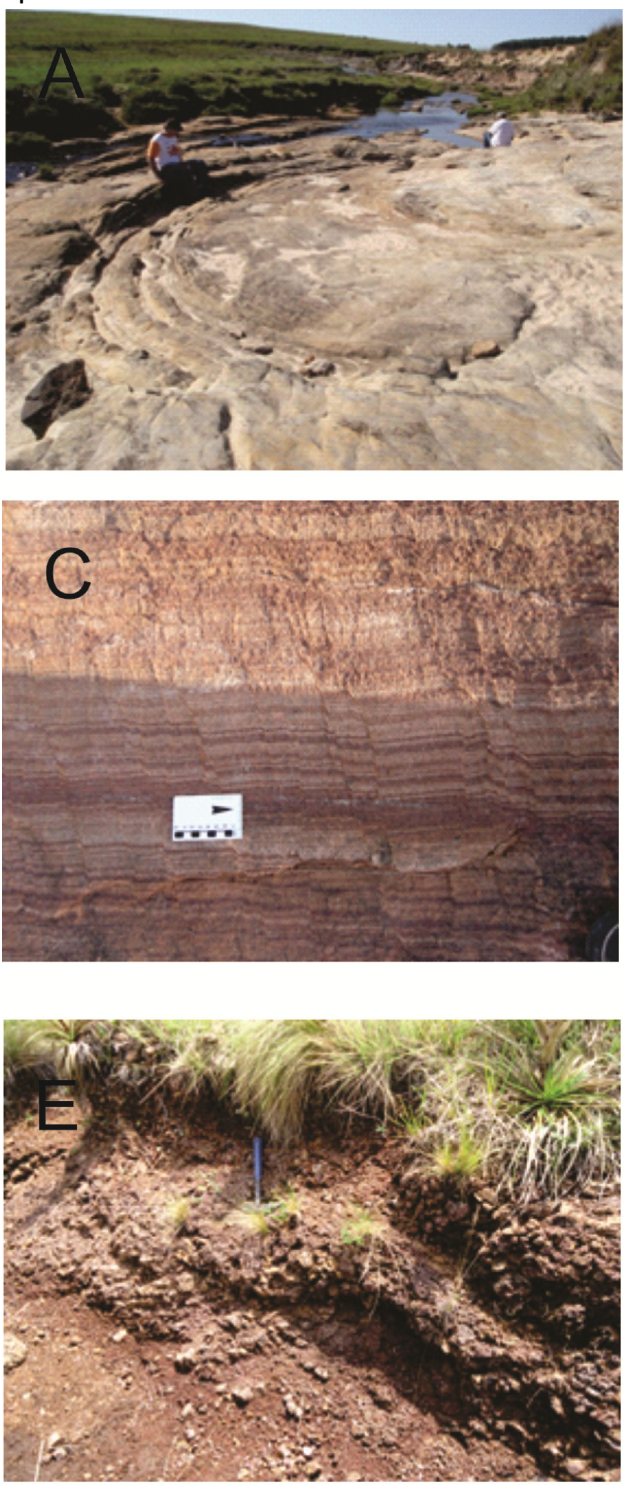

Uma nova estratigrafia é proposta para o local em Simões et al. (no prelo). Os afloramentos de arenitos homogêneos apresentam atitudes de acamamento para o interior da estrutura e os basaltos ocorrem por baixo destes, numa conformação côncava em forma de bacia. Estudos petrológicos auxiliaram na comprovação da estrutura de impacto, apresentando em afloramentos e amostras falhas e dobras, que somente ocorrem na região circular afetada pela deformação (Figuras 3 A, B, C, D, E). Em amostras e lâmina são reconhecidas fraturas preenchidas por material alóctone, com presença de quartzo em meio aos basaltos, caracterizando uma deformação pós-resfriamento dos basaltos e com preenchimento posterior das fraturas, similares a peperitos (Figura 3F).
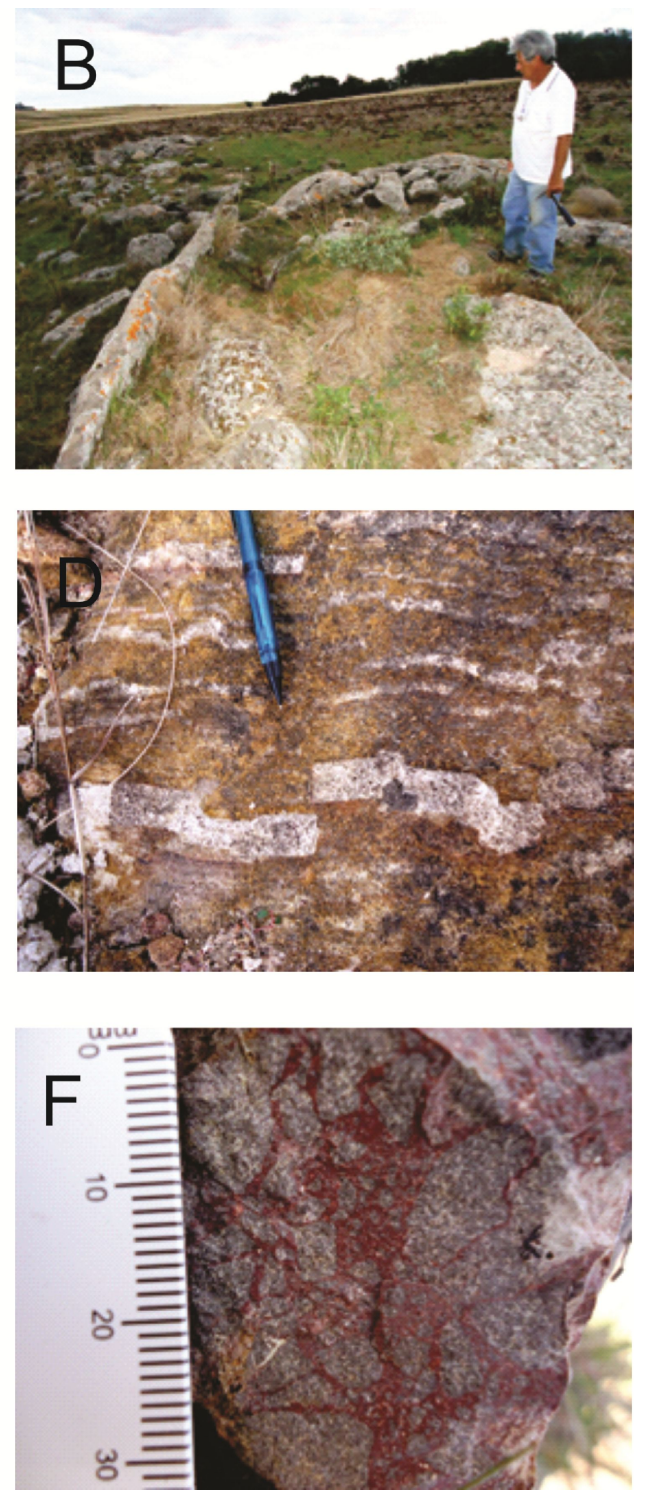

Figura 3 - A) Dobras dômicas no centro da estrutura, que ocorrem no arenito laminado. B) Dobras dômicas, no arenito homogêneo, ocorrente na parte SW da estrutura. C e D) Falhas com separação destral, foto em planta, no arenito laminado que ocorre no centro da estrutura. E) Dobras em basalto, na parte SE da estrutura. F) Feição deformacional rúptil no basalto, com fraturas preenchidas por material alóctone, composto principalmente por feldspatos, piroxênios e quartzo. 
O conjunto de cristas que forma a serra denominada Cerro do Jarau é composto por arenitos com pequeno grau de silicificação, mais coesos, que sustentam a serra, denominados por Simões et al. (no prelo) como homogêneos (Figura 3B). No centro da estrutura é reconhecido um arenito laminado que apresenta feições de deformação caracterizadas como falhas com separação destral e sinistral e dobras dômicas(Figuras 3 A, C e D).

As feições de deformação caracterizadas refletem a deformação de alto grau nas rochas.

\section{CARACTERIZAÇÃO DO GEOSSÍTIO}

\subsection{Generalidades}

O geossítio tem aproximadamente $8 \mathrm{~km} \mathrm{de}$ diâmetro, compreendendo uma área de $50 \mathrm{~km}^{2}$. Já foi contemplado em diversos artigos científicos, dissertações de mestrado e trabalhos de conclusão de curso em diversas áreas de conhecimento. Atualmente é tema do doutorado da primeira autora.

Trata-se de excepcional exemplo de cratera de impacto onde é possível notar a deformação nas rochas. Suas cristas elevadas, com cota de 200 metros chamam atenção na paisagem regional,
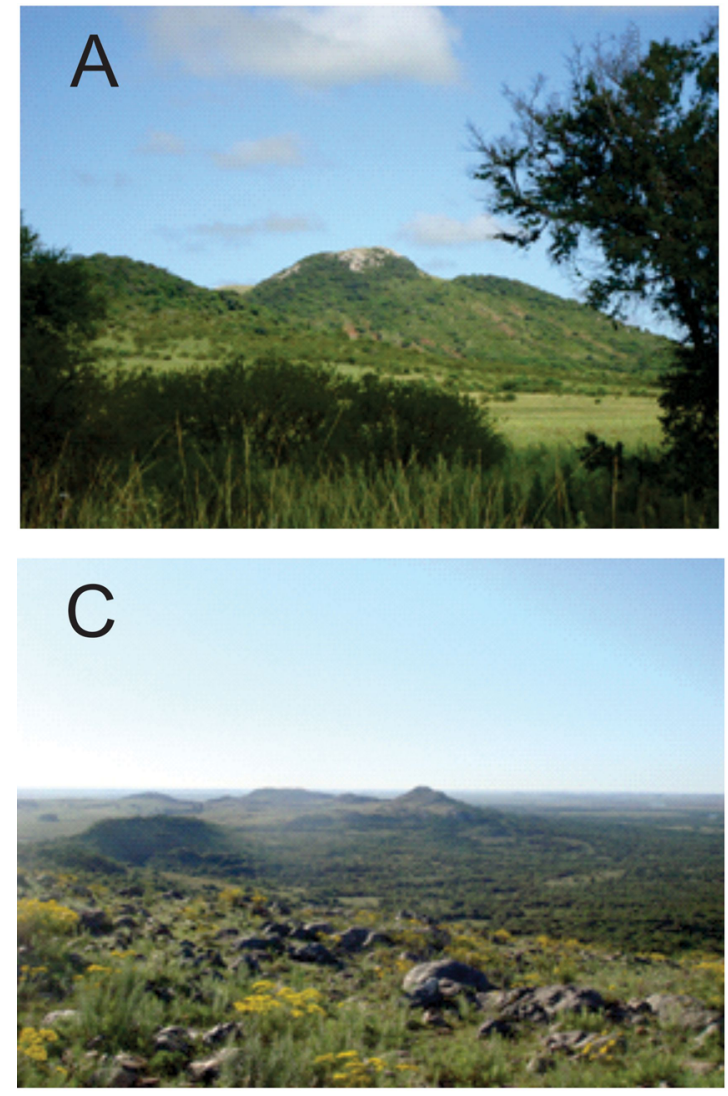

constituindo uma janela estratigráfica estrutural local (Figura 4 A, B, C e D).

O bioma regional conta com cerca de 102 espécies de mamíferos, 476 de aves e 50 de peixes, característicos dos pampas (IBAMA2007), a vegetação é dominada por gramíneas e arbustos, com árvores de pequeno porte.

\subsection{Valor científico}

Crateras de impacto são estruturas formadas quando um planeta ou satélite é atingido por meteoritos, asteróides ou cometas. Estudos planetários mostraram que não só a Lua como também todos os corpos sólidos do nosso Sistema Solar sofreram intenso bombardeio por corpos desses tipos durante sua história (Crósta 2006). Embora a Terra tenha sido consideravelmente bombardeada, principalmente nas fases iniciais de sua história (antes de $4 \mathrm{Ga}$ ), todo esse registro não se encontra preservado devido à dinâmica intensa da superfície de nosso planeta. A maioria das crateras são obliteradas pelos processos de erosão e sedimentação, bem como pela atividade vulcânica, tectônica e humana, como minerações, embora hoje sejam reconhecidas cerca de 181 crateras em todo planeta.
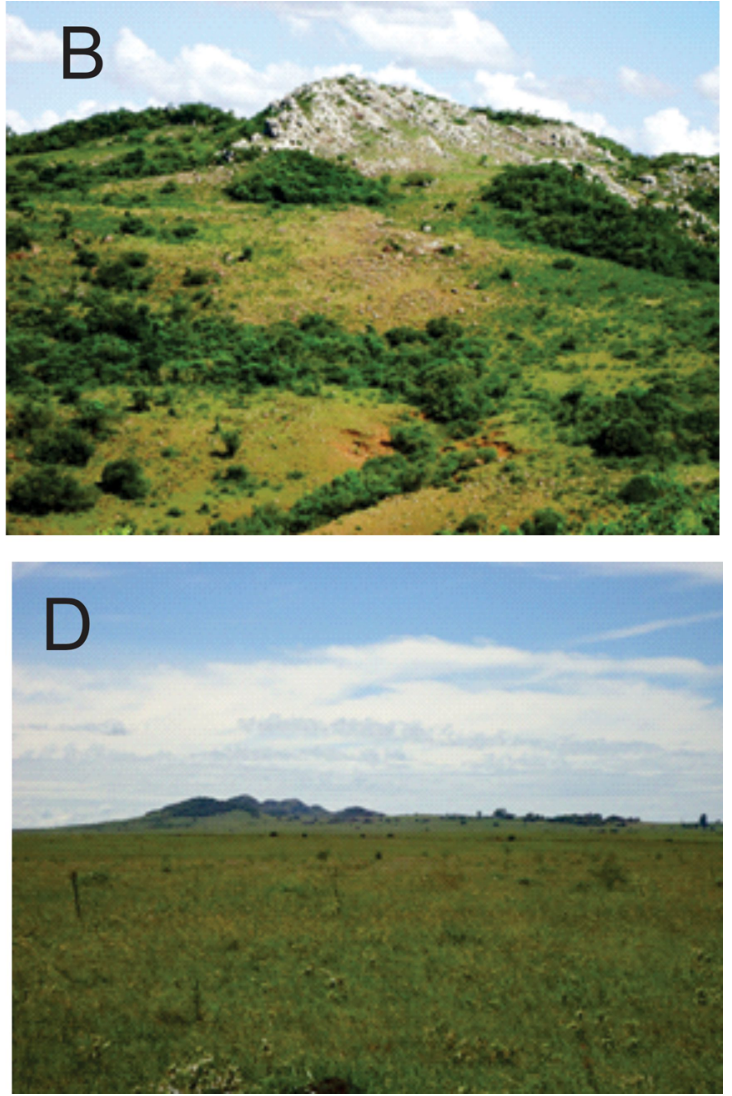

Figura 4 - A) Vista do Cerro do Jarau de Norte para Sul, onde se pode verificar que a serra é anômala e pontual na região. B) Afloramentos no topo da serra de arenito homogêneo à esquerda e basaltos à direita na parte inferior da fotografia. C) Vista da feição semi-circular que se destaca na região dos pampas. D) Vista das serras proeminentes. 
No Brasil são conhecidas 7 crateras de impacto e várias outras que possivelmente foram formadas pela colisão meteorítica, mas que ainda necessitam de estudos conclusivos. Apenas três eram conhecidas em basalto no Planeta, sendo o Cerro do Jarau a quarta comprovada.

\subsection{Valor cultural}

O Cerro do Jarau é objeto de estudo de arqueologia e história desde a década de 1990. No local são frequentemente encontrados artefatos feitos por índios, como machados de pedra e bolas de boleadeiras (Figura 5 A). Durante a Guerra dos Farrapos, as tropas de Bento Gonçalves utilizavam o local para refúgio devido às suas características propícias para alojamento. $\mathrm{Na}$ borda leste da estrutura existe um muro de arenito construído pelas tropas, com quilômetros de comprimento, que se extende até o topo do Cerro. No centro da estrutura próximo da serra existem baias com as paredes construídas por blocos de arenito que serviam para confinar animais.

A região conta ainda com a lenda da Salamanca do Jarau, de Simões Lopes Neto, que até hoje instiga o imaginário da população devido ao exemplo palpável da gruta onde a Salamanca e seu amante moraram (Figura5 B e E), essa gruta fica localizada no topo do Cerro sendo visitada pelas escolas da região. Na cidade de Quaraí a figura da Salamanca e do Cerro estão retratadas em diversos pontos, como no muro da Escola Municipal (Figura $5 \mathrm{C}$ ), num totem na entrada da cidade e no prédio da Prefeitura. Devido ao grande conhecimento populacional da lenda da Salamanca, um filme com roteiro baseado na lenda foi gravado no local (Figura 5 D).

A feição geomorfológica do Cerro do Jarau, que contrasta com o Pampa levou os historiadores e escritores relacionarem o local com algo extraordinário, referindo-se ao Cerro como algo "Divino", as lendas são comuns entre os moradores da região e, em especial, sobre a Gruta da Salamanca, onde as pessoas brincam até hoje que quem entrar lá não sairá mais.

O resumo a seguir é de autoria de Roberto Cohen e foi retirado do livro "Mitos e Lendas do Rio Grande do Sul", de Antonio Augusto Fagundes (Martins Livreiro Editor, 1996):

\section{Salamanca do Jarau}

No tempo dos padres jesuítas, existia um moço sacristão no Povo de Santo Tomé, na Argentina, do outro lado do rio Uruguai. Ele morava numa cela de pedra nos fundos da própria igreja, na praça principal da aldeia. O sacristão conhece a Teiniaguá na forma de uma lagartixa com a cabeça de fogo, $e$ um rubi na testa, colorada como um carbúnculo e a leva para a sacristia. À noite quando as sombras finalmente desceram sobre a aldeia, ele não se sofreu: destampou a guampa para ver a Teiniaguá. Aí, o milagre: a Teiniaguá se transformou na princesa moura, que sorriu para ele e pediu vinho, com os lábios vermelhos. Ora, vinho só o da Santa Missa. Louco de amor, ele não pensou duas vezes: roubou o vinho sagrado e assim, bebendo e amando, eles passaram a noite. Aconteceu assim até que os padres finalmente desconfiaram e numa madrugada invadiram a cela do sacristão. A princesa moura transformou-se em Teiniaguá e fugiu para as barrancas do rio Uruguai, mas o moço, embriagado pelo vinho e de amor foi preso e acorrentado.

No dia da execução do sacristão, todo o Povo se reuniu diante da igreja de São Tomé. Então, lá das barrancas do rio Uruguai a Teiniaguá sentiu que seu amado corria perigo. Aí, com todo o poder de sua magia, começou a procurar o sacristão abrindo rombos na terra, valos enormes, rasgando tudo. $O$ que se viu foi um estouro muito grande, nessa hora, parecia que o mundo inteiro vinha abaixo, houve fogo, fumaça e enxofre e tudo afundou e tudo desapareceu de vista. E quando as coisas clarearam a Teiniaguá tinha libertado o sacristão e voltado com ele para as barrancas do rio Uruguai. Assim, foram parar no Cerro do Jarau, no Quarai, onde descobriram uma caverna muito funda e comprida. $E$ lá foram morar, os dois.

Essa caverna, no alto do Cerro, ficou encantada. Virou Salamanca, que quer dizer "gruta mágica", a Salamanca do Jarau. Quem tivesse coragem de entrar lá, passasse 7 Provas e conseguisse sair, ficava com o corpo fechado e com sorte no amor e no dinheiro para o resto da vida. Na Salamanca do Jarau a Teiniaguá e o sacristão se tornaram os pais dos primeiros gaúchos do Rio Grande do Sul.

\subsection{Valor educacional}

O Cerro já é utilizado por faculdades e escolas da região para educação ambiental e ecológica, ocorrem visitas principalmente ao redor da gruta da Salamanca, visando integrar o conhecimento cultural e histórico com a geomorfologia, fauna e flora.

Para a população da região o Cerro do Jarau tem um valor educacional alto em relação à preservação ambiental. Para a comunidade científica é de grande interesse geológico por se tratar de uma estrutura de impacto com interesse arqueológico agregado.

Há a possibilidade de coleta de amostras de rochas sem danificar o sítio, principalmente para uso científico. 


\subsection{Valor turístico}

Com local para estacionamento e fácil acesso, as serras e a gruta são, por vezes, visitado por turistas do Estado do Rio Grande do Sul que conhecem a lenda da Salamanca do Jarau em busca da gruta da Salamanca, além de turistas relacionados a travessias (Figura $5 \mathrm{~F}$ ).

O público potencial para o Cerro do Jarau, exclusos os cientistas, são cerca de 25.000 habitantes na cidade de Quaraí, 70.000 na cidade de Artigas-UR, que faz divisa com Quaraí, 83.000 em Santana do Livramento, onde se localizam diversas faculdades e 124.000 em Uruguaiana. Como o Cerro do Jarau fica na divisa do Brasil com o Uruguai o fluxo de pessoas que transitam pelo local é
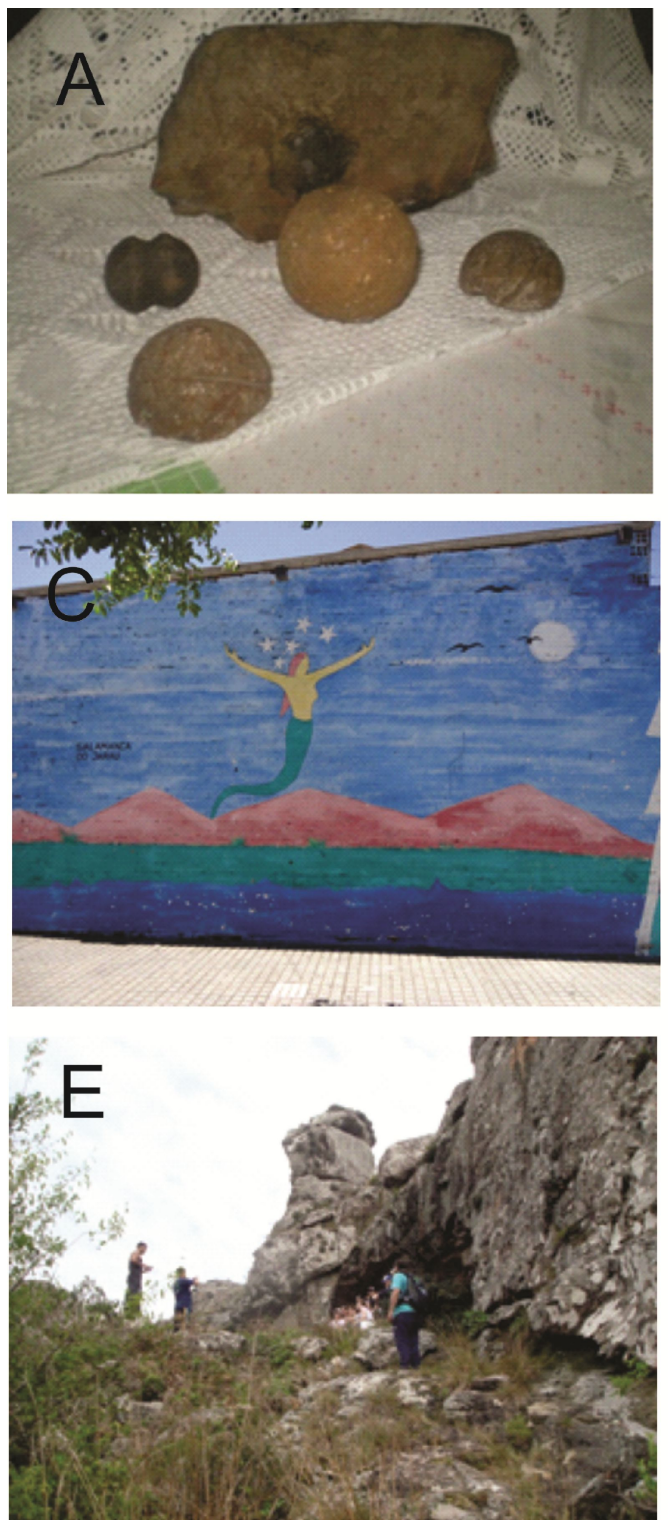

Figura 5 - A) Machado e bolas de boleadeiras encontradas na região do Cerro do Jarau, artefatos manufaturados por índios que ali viveram. B) Livro de Simões Lopes Neto, A Salamanca do Jarau, com a primeira edição em 1913. C)Muro da Escola Municipal em Quaraí, com a Salamanca e os morros do Cerro do Jarau. D) Filme Cerro do Jarau, de Beto Souza, 2005. E) Gruta da Salamanca do Jarau com visita de alunos e professores do ensino médio da cidade de Santana do Livramento, que dista $100 \mathrm{~km}$ do Cerro do Jarau. F) Cavalgada realizada na região central do Cerro do Jarau, com vista para a serra.

extremamente alto. Mas como o local não possui infraestrutura, não é comum os "turistas de passagem" visitarem o local.

Quaraí, a cidade mais próxima, localiza-se a 20 $\mathrm{km}$ do local, com infraestrutura turística, como hotéis e restaurantes. Uruguaiana localiza-se a cerca de $100 \mathrm{~km}$ e também oferece aos visitantes infraestrutura com redes de hotéis, restaurantes e freeshops.

O Cerro é utilizado para turismo de aventura e travessiasCom o valor histórico agregado ao Cerro do Jarau, há fazendas que fazem passeios turísticos na região, que vão desde arvorismo, caminhadas pelo Cerro a cavalgadas (Figura $5 \mathrm{~F}$ ).
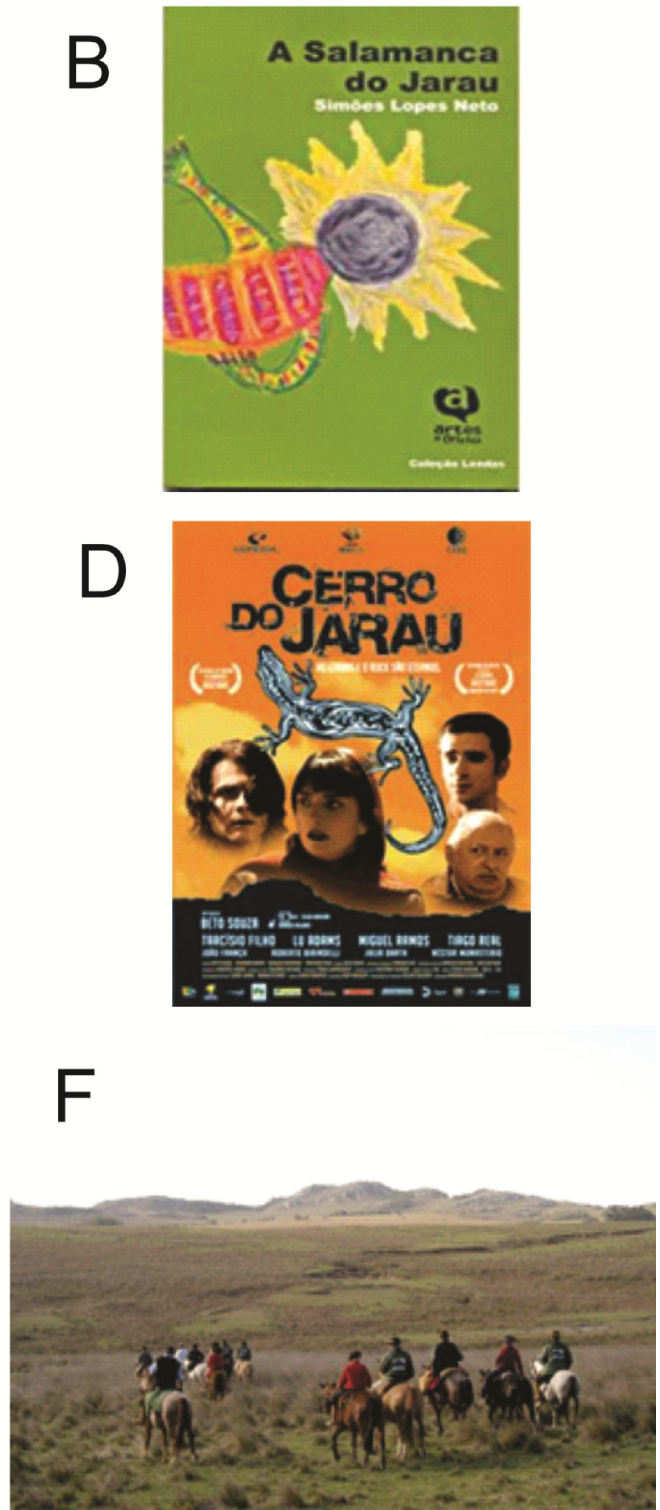


\subsection{Discussão}

Segundo Gray (2008) o Cerro do Jaraupode ser classificado como um Geossítio de exposição, que é aquele que permite observar na superfície um fenômeno geológico extenso em profundidade. Neste caso, as medidas de gestão estarão relacionadas àacessibilidade ao local de exposição principal. As ações de conservação poderão passar pela limpeza de vegetação e proteção frente a fenômenos de degradação.

Faz-se necessária a divulgação do geossítio em âmbito nacional e internacional, seja em jornais, revistas, folders, programas de televisão, internet, placas com explicações sobre a formação e principalmente aulas para as escolas municipais. 0 Cerro por diversas vezes é destaque no jornal da cidade de Quaraí, sendo indagada sua origem ou pelo fator turístico associado. A população local deverá ser informada sobre a geologia por meio de palestras, rádio ou jornal. Com a educação e valorização de cada cidadão que habita o local, o primeiro passo para o conhecimento da geologia será dado.

Para a geoconservação do local são necessárias obras de infraestrutura para receber turistas, bem como construção de banheiros e indicação de trilhas. Além de nos afloramentos vulneráveis serem efetuadas ações para assegurar sua integridade.

Segundo o índice de desenvolvimento humano de cada munícipio acerca do Cerro do Jarau (Tabela 1), as duas cidades próximas apresentam índices muito bons em relação à média nacional, o que favorece ações relacionadas á geoconservação e geoturismo, tendo em vista que a maioria da população da cidade de Quaraaí conhece o Cerro e suas histórias, e hoje com a divulgação em jornal local e entrevista na rádio da cidade também já conhecem a origem da estrutura.

Tabela 1 - Índice de desenvolvimento humano. Fonte: Atlas do Desenvolvimento Humano no Brasil (2013) http://atlasbrasil.org.br/2013

\begin{tabular}{|l|c|c|c|c|}
\hline & IDHM & IDHM & IDHM & IDHM \\
\hline Local & & Renda & Longevidade & Educação \\
\hline & $(2010)$ & $(2010)$ & $(2010)$ & $(2010)$ \\
\hline Brasil & 0.727 & 0.739 & 0.816 & 0.637 \\
\hline Quaraí & 0.704 & 0.673 & 0.852 & 0.609 \\
\hline Uruguaiana & 0.744 & 0.722 & 0.863 & 0.661 \\
\hline
\end{tabular}

O local é utilizado para criação de animais e agricultura, não oferecendo risco às feições geológicas, apresenta fragilidade nos afloramentos de dobras nos arenitos laminados, nos quais não épossível a retirada de amostras nem seria indicado que estas fossem pisoteadas. Os arenitos laminados, presentes no centro da estrutura, onde os elementos estruturais são mais presentes e de fácil reconhecimento são naturalmente erodidos pelo intemperismo, não havendo possibilidade de conter este efeito natural. A serra é sustentada por arenitos coesos e levemente silicificados não possibilitando que as feições sejam descaracterizadas com o uso por turistas, mas, é necessário que as trilhas sejam indicadas.

\section{CONCLUSÕES}

O geoturismo, na sua abordagem mais moderna, é uma forma de turismo sustentável, que atrai pessoas interessadas não apenas em conhecer os aspectos geológicos de uma região, mas também a forma como estes valores relacionam-se com o seu patrimônio material e imaterial. A II Conferência sobre Crateras de Impacto e Astrogeologia Árabe, realizada em Marrocos (2011) teve como parte de seu programa o tema "Geoturismo e Conservação do Patrimônio relacionado a crateras de impacto" e diversos eventos relacionados às geociências têm incluído aspectos relacionados ao tópico. A cratera de Ries na Alemanha é um sítio geoturístico, bem como a cratera de Vredeford, na África do Sul. No Brasil, as crateras deDomo de Araguainha-MT, Vista Alegre-PR e Domo do Vargeão-SC são citadas no SIGEP (Comissão Brasileira de Sítios Geológicos e Paleobiológicos) e algumas fazem parte dos georoteiros dos Estados onde estão situadas, como é o caso de Vista Alegre-PR. Estas ações acrescentam a importância da preservação de feições geológicas excepcionais.

Neste sentido, a região do Cerro do Jarau constitui-se num bom exemplo de geossítio no qual o patrimônio geológico pode associar-se ao patrimônio imaterial e impulsionar o turismo local. A cratera de impacto em questão é a quarta reconhecida no planeta em rochas basálticas e tem como principais atrativos estruturas de deformação bastante visíveis e cujo reconhecimento pode ser feito, com alguma orientação, por visitantes interessados. Além disso, a região tem sido alvo de estudos arqueológicos diversos que buscam registros importantes de sua história recente e possui lendas associadas diretamente à paisagem. Adicionalmente, recebe excursões de campo de escolas em busca de atividades ligadas ao estudo do meio e à Educação Ambiental. Portanto, o interesse científico alia-se, neste caso, aos valores pedagógico, turístico e histórico, criando "links" entre estes e gerando um cenário bastante propicio para o Geoturismo numa região que não é um destino turístico tradicional. 
Crateras de impacto são registros do tempo geológico e sua preservação deve ser conjunta com estudos científicos para a compreensão dos processos evolutivos da Terra, bem como para servir de exemplo natural acerca dos efeitos do impacto de um meteorito. No caso do Cerro do Jarau, esta preservação é essencialpara assegurar o acesso, em boas condições de observaçãoaos utilizadores, sejam cientistas, estudantes ou visitantes.

\section{AGRADECIMENTOS}

Agradecemos à Fapesp pelo apoio financeiro (projeto 2010/51715-1) e ao CNPq pela bolsa de doutorado.

\section{REFERÊNCIAS}

Brilha, J. B. R. (Eds) 2005. Património Geológico e Geoconservação: a Conservação da Natureza na sua vertente Geológica. 1. Ed. Viseu: Palimage, 2005. V. 1. 190p.

Crósta, A. P. 2006. Crateras meteoríticas no Brasil. Textos de Glossário Geológico Ilustrado. Em: http:// www.unb.br/ig/glossario acessado em novembro de 2013.

Crósta, A.P., Lourenço, F.S., Priebe, G.H. 2010. Cerro Jarau, Rio Grande doSul: a Possible New Impact Structure in Southern Brazil. In: Roger L. Gibson \& Wolf U. Reimold (Eds.) Large Meteorite Impacts and Planetary Evolution IV. The Geological Society of America Special Paper \# 465.

Franciscato, M. M. 2011. O turismo rural no município de Quaraí e suas relações com as atividades agropastoris. Trabalho de conclusão de curso na Faculdade de ciências econômicasUniversidade Federal do Rio Grande do Sul-UFRGS. 42 pp.

French, B.M. \&Koeberl, C. 2010. The convincing identification of terrestrial meteorite impact structures: what works, what doesn't, and why. Earth Science Rewievs, 98:123-170.

Gray, M. (2008). Geodiversity: developing the paradigm. Proceedings of the Geologists; Association, 119, 287-298.

Grehs, S.A. 1969. Aspectos Geológicos e geomorfológicos do Cerro do Jaraú, Rio Grande do Sul. In: SBG, Congresso Brasileiro de Geologia, 23, Anais, p.265-272.

Hose, T. A. 1995.Selling the Story of Britain's Stone, Environmental Interpretation 10: 16-17.

Hose, T.A. 2008. Towards a history of Geotourism: definitions, antecedentes, and the future. In: C.V. Burek\& C.D. Prosser (Eds.) The History of Geoconservation. GeologicalSocietySpecialPublication 300: 37-60.

IBAMA 2007. Relatório Final do Pampa. PROBIO/MMA www.ibama.gov.br Acessado em 10 de novembro de 2013.

Lemes, D. P., Pires, C. A. da F. 2009. Classificação geomorfológica do município de Quaraí-RS e as áreas de ocorrência mineral. Geografia: Ensino \& Pesquisa, Santa Maria, v. 13 n. 2, p. $197-$ 208.

Lisboa, N.A., Oliveira, M.T.G., Schuck, M.T.G.O., Tramontina, H.C. 1987. Reconhecimento geológico da região do Jarau, Quaraí, RS. In: SBG, Simpósio Sul-Brasileiro de Geologia, 3, Atas, 1: 319-332.

Lisboa N.A. \&Schuck M.T.G.O. 1988. Caracterização de formas padrões estruturais no Grupo São Bento da Bacia do Paraná no Rio Grande do Sul em imagens orbitais e suborbitais. In:
SBG-Simpósio Brasileiro de Sensoriamento Remoto, Anais, 2: 323-333.

Loczy, L de \& Ladeira, E.A.1976. Geologia estrutural e introdução a Geotectônica. Editora 528p. (Pg 216 e 217).

Lourenço F.S. (2007) Caracterização Geológica da Possível Estrutura de Impacto do Cerro do Jarau- Região oeste do Estado do Rio grande do Sul. Trabalho de conclusão de curso IG- Universidade Estadual de Campinas-UNICAMP. 73p.

Moreira J.C. 2011. Geoturismo e Interpretação Ambiental. Editora da UFPG, 157p.

Moreira J.C. 2010. Geoturismo: uma abordagem históricoconceitual. Turismo e Paisagens Cársticas 3(1), 5-10.

Moreira, H.L., Freitas, P.R.S., Nunes, A.B. 1980. Geologia da Estrutura de colapso do Jarau. In: Congresso Brasileiro de Geologia, 31, Anais, 5: 2684-2690.

Nascimento, M.A.L., Ruchkys, U.A., Mantesso-Neto, V. 2007. Geoturismo: um novo segmento do turismo no Brasil. Global Tourism 3(2):

NationalGeographic (2009) AboutGeotourism.http:// travel.nationalgeographic.com/travel/sustainable/ about_geotourism.html (Acessadoem 10/05/2013)

Newsome D; Dowling R. 2006.Geotourism. Elsevier Butterworth Heinemann, Oxford, $260 p$

Newsome D.\&Dowling R.K. 2010.Geotourism - The Tourism of Geology and Landscapes.GoodfellowPublishersLtd., Oxford, $246 \mathrm{p}$.

Philipp, R. P., Rolim S. B. A., Sommer, C. A., Souza Filho, C. R. de, Lisboa, N. A. 2010. Aestrutura de impacto do Cerro do Jarau, Quaraí, RS. Ver. Bras. Geoc. 40 (4): 468-483.

Newsome, D. \& Dowling, R. 2006.The scope and nature of geotourism. In: Dowling, $R$ e Newsome, D.(edits.) Geotourism. Elsevier Butterworth Heinemann, Oxford. 260 p.

Silva, B. G. da; Pes, J. F.; Milder, S.E.S. 2012 A complexidade produtiva nas estâncias da campanha do Rio Grande do Sul. Estudios Históricos-CDHRPyB- Año IV-julio 2012- ${ }^{\circ} 8$. Uruguay.

Sánchez, J.P., Simões, L.S.A. 2007. Curso de guia turístico com enfoque em geologia básica e astroblemas para estudantes das cidades de Ponte Branca e Araguainha-MT. In: Simpósio de Ensino e Pesquisa em Ensino e História de Ciências da Terra, 2007, Campinas.

Sánchez, J. P., Simões, L. S. A., Martins, L. E. B., Crósta, A. P. 2013. Geologia do Astroblema Cerro do Jarau: Implicações Estratigráficas.VIII Simpósio Sul Brasileiro de Geologia. In: Anais.

Simões, L. S. A.; Sánchez, J. P.; Martins, L. E. B.; Crósta, A. P.2012. Geologia da Região do Cerro do Jarau-RS. Novas propostas. (Em preparação).

Schuck, M.T.G.O., Lisboa, N.A. 1987. Identificação de padrões Estruturais no Grupo São Bento, Quaraí, RS, através da Análise de Imagens orbitais e sub-orbitais. Pesquisas 20. p.524.

Thomasi, D. I. 2010. Arqueologia Histórica: os metais da estância Velha do Jarau. Dissertação de mestrado no Programa de pós-graduação em patrimônio cultural da UFSM. 131pp.

Contribuição ao II Simpósio Brasileiro de Patrimônio Geológico

I Workshop Brasileiro de Patrimônio Geológico Construído

24 a 28 de setembro de 2013, Ouro Preto, MG 